\title{
A Rare Complication of Central Venous Catheter Extravasation in a Preterm Neonate: Hemidiaphragmatic Paralysis
}

\author{
C. Hobson, $\mathrm{MD}^{1,2}$ \\ D. Dubillot, $M D^{1,2}$ \\ H. Lardy, MD, $\mathrm{PhD}^{1,3}$ \\ D. Sirinelli, MD, $\mathrm{PhD}^{1,4}$ \\ E. Saliba, $\mathrm{MD}, \mathrm{PhD}^{1,2}$ \\ E. Lopez, MD, $\mathrm{PhD}^{2}$
}

${ }^{1}$ University François Rabelais, Faculty of Medecine, Tours, France

${ }^{2}$ Neonatal and Pediatric Intensive Care Unit, Hôpital Clocheville,

Tours, France

Address for correspondence Claire Hobson, MD, Paediatric Hospital Clocheville, Neonatal Intensive Care Unit, 49 Boulevard Beranger,

3 Pediatric Surgery Department, Hôpital Clocheville, Tours, France 37000 Tours, France (e-mail: claire.hobson@etu.univ-tours.fr).

${ }^{4}$ Pediatric Radiology Department, Hôpital Clocheville, Tours, France

Am J Perinatol Rep 2017;7:e65-e67.

\author{
Abstract \\ Keywords \\ - diaphragmatic \\ paralysis \\ - neonate \\ - central venous \\ catheter \\ - diaphragmatic \\ plication
}

We report a case of a preterm neonate born at 26 weeks' of gestation diagnosed with unilateral diaphragmatic paralysis. This paralysis was a consequence of a phrenic nerve injury due to extravasation of hyperosmolar parenteral nutrition fluid in the upper thorax. Chest X-rays and ultrasonography confirmed the diagnosis. The neonate was treated with prolonged respiratory support and did not require surgical treatment. This report describes a case of hemidiaphragmatic paralysis as a complication of central venous catheter insertion. In neonates, spontaneous recovery of diaphragmatic paralysis is possible. This study concludes that recovery of extravasation injury-induced phrenic nerve palsy in the context of conservative management is possible.
We report a case of an $800 \mathrm{~g}$ preterm female born at 26 weeks' of gestation to a 30 -year-old mother para 2 gravida 2 . Ultrasound scans during pregnancy were normal. The pregnancy was complicated by a threat of premature delivery at 23 weeks' of gestation with rupture of membranes and chorioamnionitis.

At birth, the neonate was intubated and received intratracheal instillation of exogenous surfactant for a respiratory distress syndrome (RDS). The first chest X-ray showed signs of RDS without diaphragmatic abnormalities (-Fig. 1A). Extubation was possible at 12 hours of life relayed by nasal intermittent positive pressure ventilation (NIPPV).

Puncture for the venous catheter's placement was on the right forearm, at day 1 of life, located in central position, as confirmed by the X-ray, and a parenteral nutrition hyperosmolar fluid was infused. Decreasing respiratory support was possible on day 4 with the use of a nasal continuous positive airway pressure (nCPAP). On day 11 of life, the neonate was intubated and ventilated with high-frequency oscillatory ventilation for severe respiratory distress. Indeed, we noted a decrease in the right basal breath sound; the respiratory frequency was around $55 / \mathrm{min}$, oxygenation at $88 \%$ without oxygen therapy, the capillary blood gas showed a $\mathrm{pH}=7.35$ and a blood carbon dioxide measure at $78 \mathrm{~mm}$ $\mathrm{Hg}$. On the same day, a chest radiograph was practiced and confirmed a right pleural effusion secondary to an extravascular diffusion of the central right venous catheter in the right pleural space (-Fig. 1B). No pleural drainage was required, the catheter was removed, and another catheter was placed on the left leg. The chest radiographs performed the day after the effusion showed that the right hemidiaphragm was elevated (-Fig. 1C). At that moment, the osmolarity of the fluid was $1,136.43 \mathrm{mOsm} / \mathrm{L}$, the total volume was $56 \mathrm{~mL} / \mathrm{d}$, and it was composed of electrolytes (sodium, potassium, magnesium, calcium, and phosphor), glucose, amino acids, and vitamins.

We suspected a hemidiaphragmatic paralysis (HDP) and performed a right diaphragmatic ultrasound on day 25 of life, received

October 14, 2016

accepted after revision

February 22, 2017
DOI http://dx.doi.org/ 10.1055/s-0037-1601566. ISSN 2157-6998.
Copyright $\odot 2017$ by Thieme Medical Publishers, Inc., 333 Seventh Avenue, New York, NY 10001, USA. Tel: +1(212) 584-4662.
License terms

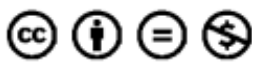




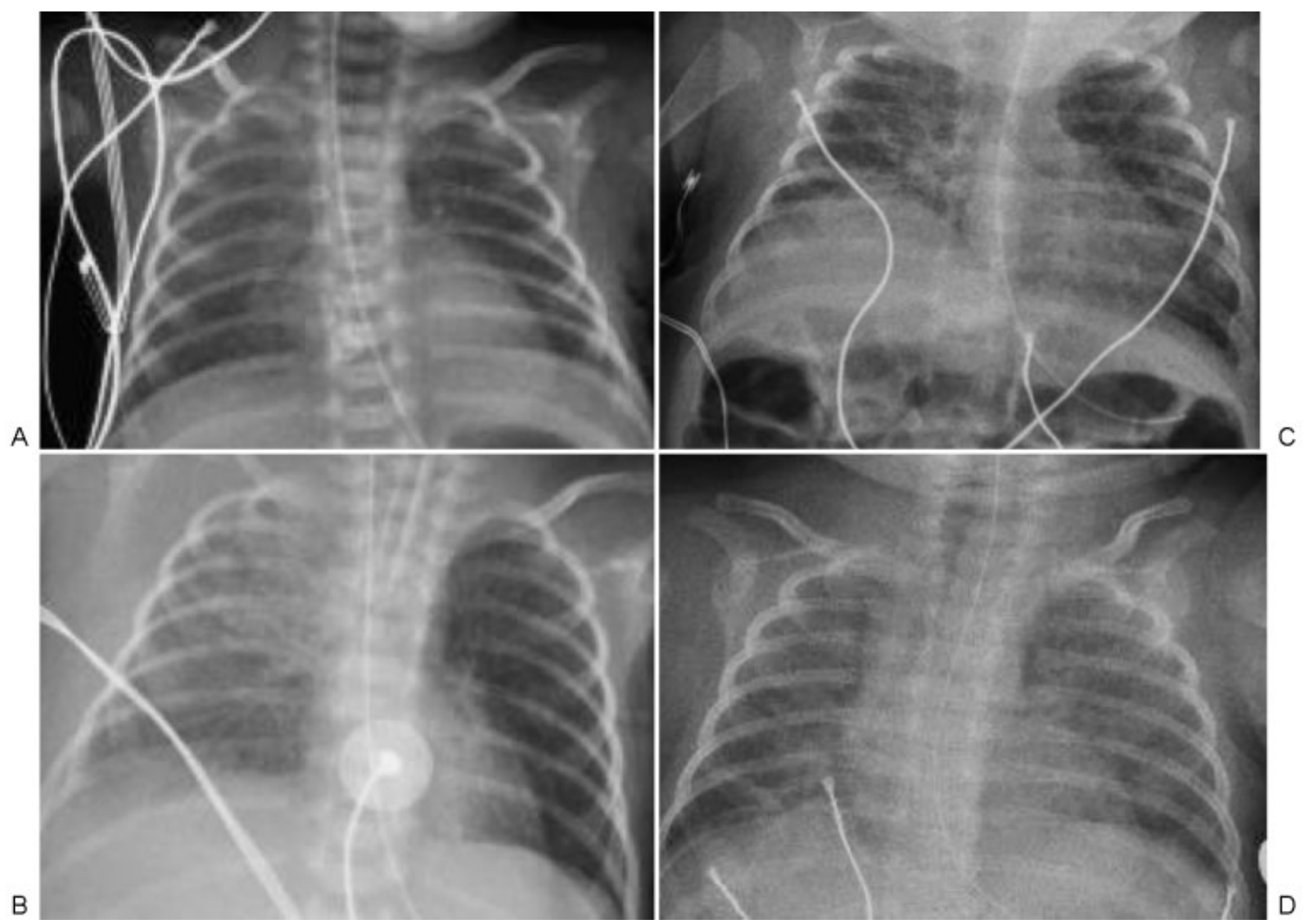

Fig. 1 (A) Chest X-ray on DOL 1: no diaphragmatic abnormalities; (B) chest X-ray on DOL 11: catheter extravasation; (C) chest X-ray on DOL 71: elevated diaphragmatic dome, and an asymmetry of position between the left and right hemidiaphragm; (D) chest X-ray on DOL 101: recovery of normal diaphragmatic position. DOL, day of life.

revealing the absence of mobility of the right hemidiaphragm, in comparison to a normal mobility of the left hemidiaphragm. The decrease of mechanical ventilation pressure was associated with the emergence of clinical signs of respiratory distress. A chest radiograph performed at these moments showed a worsening of the right hemidiaphragm's elevation, reversible when increasing the mechanical ventilation pressure. Due to the difficulties in obtaining optimal respiratory support due to the right HDP, a multidisciplinary meeting was organized to discuss a surgical intervention. Surgery carries risks, including exposing the patient's brain to the anesthetics' toxicity, infectious risk, postoperative complications, and others. Front to the low age of the infant and no insurance of a significant respiratory benefit after surgery, it was decided to proceed with conservative medical treatment consisting of prolonged respiratory support. Systemic corticosteroids were introduced on day 47 of life for bronchopulmonary dysplasia (BPD). Gradual improvement (clinical and biological) was observed and extubation was possible at day 64 of life, facilitated first by a NIPPV and then nCPAP.

The right hemidiaphragm did not elevate and stayed in normal position even after decreasing the respiratory support, as illustrated on chest radiographs. The diaphragmatic position was normal on the chest radiograph performed on day 101 (-Fig. 1D). A second ultrasonography was performed just before discharge, confirming the complete diaphragmatic recovery, and the patient was eventually discharged from the hospital at day 143 of life without any respiratory support or oxygen supplementation.

\section{Discussion}

The peripherally inserted central venous catheter, to infuse hyperosmolar nutritional fluid to neonate who cannot yet support enteral nutrition, is one of the most common invasive procedure, in neonatal intensive care units. In this case, we report a rare cause of HDP in a preterm infant, with spontaneous improvement and recovery without surgical treatment. HDP in the neonatal period can be caused by nerve injury ${ }^{1}$ during central venous catheter insertion, thoracic surgery, a traumatic delivery (brachial plexus injury ${ }^{2}$ ), and rarely by phrenic nerve injury after catheter fluid extravasation. ${ }^{3}$ Difficult breech delivery carries the highest risk of traumatic delivery-induced phrenic nerve palsy. Bilateral diaphragmatic paralysis requires further exploration as primary muscular pathology, brain stem hemorrhage, ${ }^{4}$ and hypothyroidia ${ }^{5}$ can be suspected in that case.

Only a few cases have been reported of unilateral HDP secondary to extravasation of parenteral nutrition infusion of hyperosmolar fluids through a central venous catheter. ${ }^{3,6,7}$ One case of pleural effusion caused by extravasation of nutritional fluid in the pleural space has been described $^{8}$ causing no direct HDP. Indeed, the HDP described, in this 
case, was a complication of the thoracocentesis performed to evacuate the pleural liquid. Tosello et al described two cases $^{3}$ : surgical treatment was required for one case (left diaphragmatic plication) on day 87 (postoperative recovery was favorable), in the second case, prolonged mechanical ventilation was required, and recovery was spontaneous around day 130 . A third case was reported in 1995 concerning an infant of 30 weeks' gestational age, ${ }^{6}$ corticosteroids were introduced on day 34 of life, noninvasive ventilation was required until day 45 of life, and the outcome was favorable, despite the absence of mobility of the right hemidiaphragm after medical treatment. Extravasation of fluid in the pleural space could be secondary to a local mechanical injury caused by the catheter itself, but also to the local toxicity of the infused fluids. This second hypothesis highlights the importance to check regularly, preferably by ultrasound monitoring, the catheter's position to confirm its central position, allowing the infusion of hyperosmolar fluids which cannot be used in case of a peripheral position.

Although the mechanism remains unclear, the nerve injury occurring after extravasation of an hyperosmolar fluid in the pleural space could be due to the hyperosmolarity (usually over $800 \mathrm{mOsm} / \mathrm{L}$ on a central catheter), which is thought to cause toxicity to surrounding tissues. ${ }^{9}$ Also, no information was found on the benefits of a pleural drainage in case of a low abundance pleural effusion, to diminish local nerve toxicity. HDP is suspected in the case of respiratory distress ${ }^{1,2,4,5,10}$ without any infectious or cardiovascular explanation and confirmed by chest radiograph ${ }^{3,10}$ and diaphragmatic timemotion mode ultrasound scan. ${ }^{11,12}$ On the chest radiograph, HDP is suspected from an elevated diaphragmatic dome and asymmetry of the position between the left and right hemidiaphragm. The diaphragmatic function can be evaluated by ultrasound scans, a noninvasive investigative tool which does not utilize ionizing radiation. Electromyography can also be helpful but was not performed in our case.

No specific guidelines for the treatment of this rare complication have been published. Two opinions emerge surgical treatment (plication of the diaphragm ${ }^{2,13}$ ) and medical treatment, consisting of adapted respiratory support. The use of positive pressure ventilation could maintain a pulmonary volume necessary to proper oxygenation., ${ }^{3,5}$ The indications and proper timing for diaphragmatic plication surgery remain unclear. It appears early surgery could reduce the duration of mechanical ventilation, hence reduce the exposure to toxic medication required in mechanical ventilation. However, there is no clear evidence to support this. Some authors have mentioned the advantages of early surgical intervention, ${ }^{14}$ which can indeed be discussed in our case.

In our case and in a second reported case, ${ }^{3}$ spontaneous recoveries occurred with nonsurgical treatment. The use of corticosteroids could decrease the inflammation caused by extravasation and improve both the diaphragmatic function ${ }^{6}$ and BPD, although they have to be discussed owing to their systemic effects, including neurological. When medical treatment has chosen the risk of nosocomial infections increases, ${ }^{3}$ the duration of mechanical respiratory support and hence of the hospital stay is longer. If no benefit of the corticotherapy is seen, and/or in cases of prolonged invasive mechanical ventilation, surgical treatment should be considered. Also, the spontaneous outcome is related to the irritative mechanism of the phrenic nerve, which is to differentiate from a traumatic damage.

HDP is a rare complication of the peripherally inserted central catheter, secondary to a central venous diffusion and nutritional fluid extravasation in the pleural space. In premature infants, nutritional fluid is often hyperosmolar, hence requires a central venous catheter. Considering that, we have to remain vigilant in case of a sudden respiratory distress, with no infectious explanation. Although there is no specific recommendation for the treatment of HDP, this case highlights the advantage provided by a nonoperative treatment, with a favorable outcome in the preterm neonate.

Financial Support

No financial support was received for this work.

\section{References}

1 Vest JV, Pereira MB, Senior RM. Phrenic nerve injury associated with venipuncture of the internal jugular vein. Chest 1980; 78(05):777-779

2 Bowman ED, Murton LJ. A case of neonatal bilateral diaphragmatic paralysis requiring surgery. Aust Paediatr J 1984;20(04): 331-332

3 Tosello B, Michel F, Merrot T, et al. Hemidiaphragmatic paralysis in preterm neonates: a rare complication of peripherally inserted central catheter extravasation. J Pediatr Surg 2011;46(07): E17-E21

4 Blazer S, Hemli JA, Sujov PO, Braun J. Neonatal bilateral diaphragmatic paralysis caused by brain stem haemorrhage. Arch Dis Child 1989;64(1 Spec No):50-52

5 Pollard BJ, Hain WR, Small PG. Paralysis of the right hemidiaphragm. Anaesthesia 1982;37(02):195-200

6 Williams JH, Hunter JE, Kanto WP Jr. Bhatia J. Hemidiaphragmatic paralysis as a complication of central venous catheterization in a neonate. J Perinatol 1995;15(05):386-388

7 Aggarwal S, Hari P, Bagga A, Mehta SN. Phrenic nerve palsy: a rare complication of indwelling subclavian vein catheter. Pediatr Nephrol 2000;14(03):203-204

8 Ozdemir R, Oğuz S, Uras N, et al. Phrenic nerve injury due to thoracentesis for TPN effusion in a preterm newborn: consecutive two unusual complications. Tuberk Toraks 2011;59(04):384-387

9 Hannon MG, Lee SK. Extravasation injuries. J Hand Surg Am 2011; 36(12):2060-2065, quiz 2066

10 O'Donnell CPF, Morley CJ. Paralyzed right hemidiaphragm in a newborn infant. J Pediatr 2006;149(05):730

11 Gottesman E, McCool FD. Ultrasound evaluation of the paralyzed diaphragm. Am J Respir Crit Care Med 1997;155(05):1570-1574

12 Matamis D, Soilemezi E, Tsagourias M, et al. Sonographic evaluation of the diaphragm in critically ill patients. Technique and clinical applications. Intensive Care Med 2013;39(05):801-810

13 Ribet M, Linder JL. Plication of the diaphragm for unilateral eventration or paralysis. Eur J Cardiothorac Surg 1992;6(07): 357-360

14 Ahmadpour-Kacho M, Zahedpasha Y, Hadipoor A, Akbarian-Rad Z. Early surgical intervention for diaphragmatic paralysis in a neonate; report of a case and literature review. Iran J Pediatr 2011;21(01):116-120 